\title{
Explicating Listening Difficulties and Listening Strategies of Indonesian EFL Learners
}

\author{
Fachriza Amalia Rakhman ${ }^{1} \&$ Sri Samiati Tarjana² \& Sri Marmanto ${ }^{3}$
}

\author{
${ }^{1,2 \& 3}$ Sebelas Maret University, Surakarta, Indonesia \\ Correspondence: Fachriza Amalia Rakhman, Sebelas Maret University, Surakarta, Indonesia. \\ Email: rizarakhman11@gmail.com
}

doi: 10.23918/ijsses.v6i2p51

\begin{abstract}
This study aimed at revealing listening difficulties perceived by Indonesian learners in English as a foreign language listening class. The data were collected from 6 EFL students who have studied at the English department program in a University in Indonesia. This research is qualitative research which used questionnaire, observation and semi-structured interview to gain the data. This research used a Second Language Listening Difficulties Questionnaire proposed by Anna Ching-Shyang Chang (2013) to complete the required data and the second questionnaire was Strategy Inventory for Language Learning version 7.0 for EFL learners adapted from Oxford (1990). The result of the research showed that EFL Indonesian learners face difficulties related to internal and external factors. Moreover, in tackling these difficulties, the students apply listening strategies which include both cognitive and metacognitive.
\end{abstract}

Keywords: EFL Learners, Listening Comprehension, Listening Difficulties, Listening Strategies

\section{Introduction}

Government Regulation No. 32 of 2013 concerning Amendment to Government Regulation No. 19 of 2005 Article 77J paragraph (1) c (3) stated that foreign languages, especially English, is an international language which is very important in global communication. Therefore, based on the regulation formulated above, the Ministry of Education makes regulations dealing with standard competence and basic competence of English for elementary level until Senior High School level to develop learners' communicative competence.

Most of Indonesian EFL learners have spent more than 9 years learning English but they still have difficulties. So that is why we have to propose strategies to learn it. Due to the limited time in formal education, an effective and efficient way in teaching-learning process should be proposed. One of the aims of proposing an effective and efficient way in the teaching-learning process is to form successful learners. Successful learners are those who can propose strategies in their learning to make the process effective and efficient (Cohen \& Dornyei as cited in Fauziati, 2004). The main point to differing successful learners and less successful learners is by looking up their effort to maximize their ability in listening as a means of acquisition and communication (Rost, 2001).

Moreover, Sebina and Arua (2014) stated the same point that listening is a difficult skill to be achieved and the heaviest processing demand for non-native students compared to the other skills such as writing, reading, and speaking. The reason is that while listening, the students need to store and understand the information they have heard in their short-term memory system at the same time. While in a listening test, 
they also have to write down the information to their answer sheet (Rubin, 1995). Also, several factors can contribute to make listening as a difficult skill to be mastered. Those factors are difficulties dealing with unfamiliar vocabulary, topics, register, and accent. Noise as an external factor can be also an obstacle during the process of listening (Brindley \& Slatyer, 2002; Buck, 2001).

However, in practice, although many experts said that listening is a difficult skill, it is still put less attention compared to writing or speaking (Field, 2008; Macaro, Graham, \& Vanderplank, 2007; Vandergrift, 2007; Vandergrift \& Goh, 2012; Chou, 2016). In the education sector recently, writing skill for an academic has been a matter of great concern. This is due to the Ministry of Education's regulation under Permenristekdikti 44/2015 and Circular No. 444 / B / SE / 2016 which requires an academic to have scientific publications in the form of a journal. Under that regulation, higher education institutions also compete to increase the number of scientific publications to increase the quality of the institutions. As a consequence, writing skill for an academic is more emphasized and gets more attention compared to the other skills such as listening.

Huei-Chun (as cited in Ulum, 2015) has also stated that listening skill has been ignored because listening skill is considered to be taken for granted. It will follow and develop along with other languages for example when we learn to up their effort to maximize their ability in listening as a means of acquisition and communication (Rost, 2001). Unfortunately, listening for EFL learners is often perceived as the most difficult skill to acquire because the act of listening is often implicit and ephemeral (Graham, 2003). Listening is a complicated process because it needs people who involved in listening to understand the cultural background well. They are to have a cross-cultural understanding to avoid misinformation. The language scene which can promote the success of listening is needed too. Moreover, tactics to make us easier to get the information should be applied as well.

Previous studies related to the topic were conducted. There are several previous studies which raised themes about listening strategies and listening difficulties. Golchi's (2012) research entitled Listening anxiety and its relationship with listening strategy use and listening comprehension among Iranian IELTS learners examined listening anxiety towards listening strategies used by EFL Iranian learners and its relation to their comprehension. The participants used for the research were sixty-three Iranian IELTS learners from two language institutes in Shiraz. Four instruments were applied for the research in order to collect the data. Those instruments were Background Questionnaire developed by Lee (1997), a Listening Anxiety Questionnaire developed by Kim (2000), Lee's (1997) Listening comprehension strategy and IELTS listening test. From the finding of the research, we could get the result that there was a negative correlation between listening anxiety and listening strategy used as well as listening comprehension. Besides, through this research, another result was obtained. That was low anxious learners used metacognitive strategies more frequently than high anxious learner did. Therefore, low anxious learners had better performance in listening rather than high anxious learners. In addition, female learners were revealed to have a higher level of anxiety rather than male learners. Besides, the results of this research also showed that time spent in learning English by the learners had a significant positive effect on their anxiety. It means that the more they spent time learning English, the lower their anxiety level will be.

Moreover, another research conducted by Serri et al. (2012) entitled Cognitive, metacognitive, and social/affective strategies in listening comprehension and their relationships with individual differences tried to examine learners' learning strategies including their cognitive, metacognitive and socio-affective strategies while listening to the text. It used 40 Iranian University EFL students as the participants. Four 
questionnaires were used for this research including motivation questionnaire adapted from Laine (1988), Listening strategy use proposed by Vandergrift (1997), learning style proposed by Soloman and Felder (2001) and the last was Revised edition of NEO- FFI. To sum up, the result of Serri's et al. research founded that there was a significant relation between learners' motivation level and the strategies they used in listening. In addition, Serri et al. added that learning style of the learner's affect learners' listening strategies.

This research has similiarities with the previous research in terms of listening difficulties and listening strategies. This research specifically examines EFL learners who take English as the subject of the research. This research uses case study in order to provide in depth examination. Moreover, this research also tries to examine listening difficulties together with listening strategies employed by the students in order to provide a deep research.

In conclusion, this research tried to analyze EFL learners' listening difficulties found in the EFL classroom. Moreover, it also tries to examine students' listening strategies used to overcome their problems in listening. Also, this research tries to provide suitable solutions for the difficulties found. This is interesting to explore the phenomenon that English department students, who have serious consideration in choosing English as their subject, have more exposure in English and have a high demand to master English well still find difficulties in listening which is being one of the important skills to comprehend knowledge as well as language. This research tries to answer two research questions:

1. What are listening difficulties perceived by Indonesian EFL learners in EFL Listening Classroom?

2. What are listening strategies applied by Indonesian EFL learners in EFL listening Classroom?

\section{Literature Review}

\subsection{Overview of Listening}

According to Downs (2008), listening can be defined as an intentional effort to hear or to give more attention to something we hear to gain certain information. In addition, in case of its objective to give more attention, listening is considered as a way we understand native speech at its normal speed where it involves auditory discrimination, aural grammar, selecting necessary information, remembering, and connecting to the process between sound and form of meaning (Chastain, 1971; Morley, 1972 as cited in Gilakjani, 2016). Listening is different from hearing. In listening, we have a certain intention to look for some information (Downs, 2008). While in the hearing, we do not have such a particular intention. It is only a common process of the ear in absorbing the sound waves which are then processed in the brain through the neural system. In other words, listening needs concentration. We have to focus and center our attention if we want to catch the information. While in the hearing, there is no particular intention to catch any information. When we hear, it does not mean that we listen. But, if we listen it means that we hear the sound waves. What makes those two things different are the process, intention and the portion of our focus and concentration we put in it.

Furthermore, Brown (2004) said that listening is our particular way to gain information by paying attention to the main point of what we hear, emphasizing to the important supporting points, and making a conclusion to draw overall information the speaker has said. Moreover, Goss (1982) defined listening as a process of understanding the sound that we hear and processing it into lexical elements to construct 
meaning. Everything that we heard then is processed in the brain and the output is in the form of a message. The measuring value of the success of listening is on our right response to what we have heard. If what we have caught is right, there will be no misunderstanding happened. The communication will run well. It is in line with Rost (2009), who said that listening is an important element to promote successful communication which completes the process of oral communication.

From several definitions of listening stated by the experts above, listening can be defined as an active, complicated and conscious process of getting information or message by putting attention and intention through sound produced by the speakers which are involving listeners' understanding of the context, culture and other factors such as vocabulary, grammar, pronunciation.

\subsection{Listening Strategies}

The need for strategies to be applied in learning language, more specific in learning English listening for EFL students is a must. It becomes an obligation because of the objective of students to be successful learners. According to Oxford, Chamot and O'Malley (as cited in Wilson, 2009) strategies are actions which are applied on purpose to promote students' learning process and make the learners gain information effectively. Language strategies proposed by Oxford (1990) consist of two big classifications. They are direct and indirect strategies. Direct strategies have several elements which are memory strategy, cognitive strategy, and compensation strategies. While in indirect strategies, there are metacognitive strategies, affective strategies, and social strategies.

All elements in direct strategies are strategies which process happened inside the brain. They are used immediately while we are engaging with the task. Whilst indirect strategies are strategies which are processed outside the brain, they are used more like a planner to arrange and manage our steps in applying direct strategies. To sum up, successful learners apply more strategies compared to less successful learners. Proficient listeners are likely to be able to apply many strategies to support their performance.

\subsection{Listening Difficulties Factors}

There are eight spoken language characteristics proposed by Brown (2007) which are considered to be the sources of listening difficulties that should be paid attention for since listening is strongly related to spoken language. Spoken languages have several characteristics which make it difficult compared to the written language. These characteristics might cause difficulties to the learners. They are clustering, redundancy, reduced forms, performance variables, colloquial language, rates of delivery, stress, rhythm, intonation, and interaction (Dunkel, 1991; Richard, 1983; Ur, 1984).

According to Samuel (1984), there are two factors of listening difficulties. They are external and internal factors. External factors are factors that come from outside the learners. It means those factors do not come from within the learner. External factors usually come from the environment. External factors can be learning opportunities. Besides, speaker characteristics such as how loud the voice when it is delivered can also be categorized as an external factor. Next factor is a medium factor. This factor is related to the medium at the time of listening. In a listening class, for example, the medium can be the text type, task type given by the lecturer, and the context where listening takes place. If learners do not understand the context and they have not enough knowledge about it, they will face difficulties. The text type and the task type given can also be their obstacles because if they have a tendency in a certain form of text types such 
as multiple choice or essay, they will feel pessimistic and it will affect their performance. Moreover, if they do not understand the generic structure of a particular text, they might face difficulties in understanding the meaning and comprehend the information. Those things seem trivial but they are crucial.

The last is the internal factors. Internal factors come from the listeners themselves. According to Samuels (1984), several factors can be categorized as internal factors. They are intelligent, language facilities including accuracy and automaticity in understanding the words, vocabulary, syntax, idiolect and dialect, anaphoric terms, background knowledge, speech register, anxiety, and motivation.

\section{Method}

\subsection{Design and Participant}

This research tried to examine listening difficulties encountered by EFL students in listening classroom and their listening strategies. A case study was applied for this research since the aim of this study is to provide an in-depth analysis of a certain phenomenon (Cresswell, 2002). This research used purposive sampling where 6 of 26 Indonesian English department freshmen students from one of the Universities in Indonesia were involved. They were around 19-20 years old. The participants were selected based on the result of their pre-listening test and English competency level. The participants were purposefully categorized into three groups i.e. high, medium and low. There were two students for each category. The scores of two students in high level were $83(\mathrm{P} 1)$ and $86(\mathrm{P} 2)$. The score for medium-level students were 70 (P3) and 73 (P4) while for the low-level students, the score were 66 (P5) and 50 (P6). The participants were chosen because they were still at the beginning stage of a higher level of education. It means, they were still in a transitional stage from the learning situation of senior high school to the learning situation of the higher level of education. Therefore, they should become a suitable participant since they need to be a more proficient English learner especially in listening skill where the skill will be used to comprehend knowledge. To keep participants' privacy, the name of the participants will be written as an initial. E.g. P1 for the first participant.

\subsection{Data Collection Techniques}

Questionnaires, interview, and observation were administered to collect the data. This research used two questionnaires. The first questionnaire was Second Language Listening Difficulties adapted from Anna C.S Chang (2013) and the second questionnaire was Strategy Inventory for Language Learning version 7.0 for EFL learner adapted from Oxford (1990). The questionnaires were given to 26 EFL students. There were 47 items for Second Language Listening Difficulties and 68 items for SILL questionnaire. Before the researcher spreaded the questionnaire, a pre-listening test was conducted to see the students' level of listening. The test was taken from Oxford listening placement test by Dave Allen (2004). The researcher also asked the students' listening scores to the lecturer as a consideration in determining the choice for the participants to follow think-aloud protocols. The observation was conducted when the participants have their listening class in a natural setting. This procedure was administered to find the verbal and physical signs of the students that occurred during EFL listening classroom. Then, a semi-structured interview and think-aloud protocol were used. Unlike writing or speaking, listening is a receptive skill in which we cannot see the result or the product. Therefore, the think-aloud protocol was used to gain valid data. 
Moreover, the purpose of the think-aloud protocol in this research is to provide valid data about listening strategies applied by EFL learners. In other words, this method is used to know how the students' cognitive process in solving the problems when they experience listening. Their cognitive process when listening related to their strategies.

\subsection{Data Credibility and Data Analysis}

To ensure the credibility of the data, triangulation method was used. For this research, before doing data analysis, the first step to do is to collect all the data including data from questionnaires, observation, and interview. After that, the researcher identified all of the data dealing with listening difficulties and listening strategies by transcribing it. After the needed data was collected, they were transcribed, organized and analysed.

The procedure of think-aloud protocols was held in three days. First, for high-level participants, the second day for medium-level participants and the last day for low-level participants. The session took approximately 45 minutes for each student. The participants were given the draft of the interview before the procedure was held so that the participants could understand the procedure. The process of interview and the think-aloud protocol was tape-recorded. After that, the data were transcribed and coded. The listening text for the think-aloud protocol was taken from Jack Richards' book entitled Interchange Intro (2005). This book provides complete elements of listening. There is a section for students' self-study. Unfortunately, this book is rarely used in an academic institution. Besides, this book is considered as reliable, authentic and valid. Besides, this book meets the researchers' requirements. Thus, the researcher decided to use this book as a reference.

After the data were coded, the researcher gave a copy of the transcription to the participants to check whether there was a mistake or not. The researcher asked the participants to read, check, confirm or even add additional responses. The participants were also asked to confirm the researcher's data interpretation of the participants' listening strategies. Then, the data that have been confirmed was analyzed by using open coding. The data were coded based on Oxford's (1990) taxonomy. Oxford's taxonomy was chosen due to its complete classification elements from metacognitive until socio-affective strategies.

\section{Findings and Discussion}

\subsection{Findings}

\subsubsection{Listening Difficulties encountered by Indonesian EFL learners}

After administering data collection and coding it, the result of this research showed that there were several listening difficulties. They were inadequate practices outside the classroom, short-term memory problems, homophones, and speech rate.

\subsubsection{Difficulty Related to Inadequate Practice Outside the Classroom}

For EFL students in Indonesia, looking for practice outside the classroom is quite uncommon. Most of the students only receive materials inside the classroom and they rarely look for by themselves additional 
materials outside the classroom. The condition of the environment such as the lecture and the partner still cannot fully support every student to reach their best.

P1: A listening lecture is only once a week. The teaching-learning process is not full English. The lecturer often speaks in Javanese (a mother tongue of most students) sometimes in Bahasa. We interact with our friends only in Javanese and Bahasa. Never we use English although it is inside a classroom.

P2: I have no English native speaker friend here. The others are the same.

Besides, English is not a means of communication in Indonesia therefore, students have little input and a chance to practice. It makes EFL students in Indonesia mostly hard to master English although they have known and learned English for nine years.

\subsubsection{Difficulty Related to Short-term Memory}

The next difficulties perceived by EFL Indonesian students is related to short-term memory. Short term memory is the inability to retain memory for a specific period. After listening to a set of words or sentences, the students will immediately forget what they listened to before. This problem occurred by several factors. One of them is the students' inability to maintain their concentration. For several students, this might be a crucial problem. They will forget the information at the same time when they try to set their concentration to listen to the next information.

P4: Every time I listen to the recording and try to store the important point,

I start to forget the previous information I have. I feel overwhelmed.

However, this problem rarely happens when the recording is short.

The student frequently forgets the information, but, he rarely forgets the information if the text is short and slow. It means that the longer the text, the easier students will forget the information.

\subsubsection{Difficulty Related to Homophones}

Homophones are tricky for most EFL learners. EFL learners do not use English as their daily means of communication so they are not used to words in English. They are more familiar with words in their first language. They are Javanese and Bahasa. Therefore, when they meet homophones, they will be confused. For them, homophones are unclear. As a consequence, they are unable to define the words. They fail to decode and recall the new words with words that they have stored in their long-term memory system. This cause the students to forget easily the words they have listened to.

P.5: I sometimes listen to words that have the same pronunciation. I think that words are words I know before. But I was wrong. That words have different meaning as well as different spelling. I trapped and lost into my confusion.

P.6: I always try my best when it comes to homophones. It makes me worry because I am unable to catch the words. 


\subsubsection{Difficulty Related to Speech Rate}

The last difficulty is related to a speech rate. It is still difficult to catch a fast stream of words although it is from our first language. When someone speaks so fast, that makes the words the speaker utters become unclear. The listeners will center their attention only in the most important part. When they meet this situation they will try to put their attention on the unclear words, not the meaning. Finally, they will realize that they left the meaning and get nothing. Besides, they are unable to put their attention to the speaker because they have to read the question and looking for the answer at the same time.

\section{P1: The recording runs so fast with unclear pronunciation. The text is long enough. I have to divide my concentration into many parts and usually I find myself ruin everything. (1/INT/5)}

Underwood (1989) asserted that an unknown word could puzzle the students and make them miss the information because they will stop listening to look for the meaning of the unknown word. This condition mostly happened to EFL students. They will over-concentrate in what they heard. They over-think the unknown word without knowing that they ruin everything and miss the information.

The learners also use the strategy of inferencing to complete the missing parts or completing the information. All of the participants will connect a word with other words to get the meaning. They utilized the context of the sentence or unfamiliar word with other word or with its context.

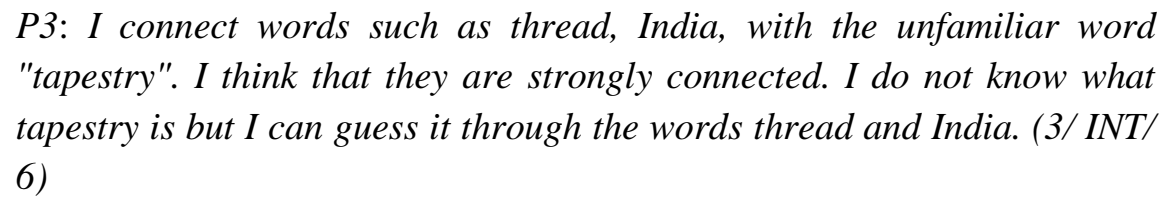

Goh (1998) stated that a top-down listening process can be found in inferencing. It is a process which is used to complete the missing part or information. Such as clarifying unfamiliar words and information when they miss listening. Therefore, inferencing by using linguistics cue is useful and applicable for EFL students while listening. It can help them to understand the text.

\subsubsection{Listening Strategies Mostly Applied by Indonesian EFL learners}

From the process of interview by using a think-aloud protocol, there are strategies applied by the students. They are note-taking, skipping and using imagery. The first strategy is note-taking. In using this strategy, the students must write down the important clues, or keywords related to the topic. In writing the clues, students apply various ways. Most of them write it on their sheet paper, or directly on their desk because they were not allowed to make any scribble on the paper when they have a listening test. P1 and P2 did it mostly when they are listening. They did it on their answer sheet.

P1: I did it of course. On my answer sheet because I do not want to miss anything. (1/INT/3)

P2: My answer sheet always full of scribble. I did it and I erase them before I submit my answer sheet. (2/INT/3)

P3 said that she likes to write abbreviation of what she heard. Abbreviation can be effective when we listen to text containing details of items. 
P3: I frequently write abbreviation. It is much more simple and fast.

(3/INT/3)

Those statements give us the indication that note-taking is considered as an easy and favorite strategy. They use it to identify the important points of the text. They use this strategy to keep them 'stay on track'. Therefore, by doing this strategy students can take the gist of the text and get the right information. They also can handle their short term memory and do not miss any information. They also can learn how to maintain their concentration and review their answers by doing note-taking during listening.

A note-taking strategy is closely related to concentration. Concentration is the basic and essential foundation of all listening strategies. Thus, paying attention and concentration during listening is a mustapplied strategy. All participants said that they focus and pay utmost attention when they start listening. They listen to the content and look for the main idea. When the listening section starts, they try not to think anything else other than the recording.

The next frequently used listening strategy is skipping. Skipping means that we ignore the unfamiliar word to lessen or avoid the difficulty that may appear. The students used this strategy because they want to keep their concentration. By ignoring the unfamiliar word, they will not lose the information.

P6: I try my best to ignore any difficult and unfamiliar words. That makes me stay on my track. It triggers my anxiety if I put my attention too much on difficult terms. (6/INT/4)

The same idea also was stated by P5. He said that by doing skipping, he did not lose the important point or the keywords.

P5: I do skipping. I skip all the words that puzzle me. I do not want to miss important keywords. If I was distracted by those words, I will run out of time and ruin everything. I will not be able to fill a number. (5/INT/4)

From the statement of the participants, we know that this listening strategy is useful to get the gist or the point of the text. However, this strategy will only be effectively used if the topic of the text and its levels are quite familiar to the students.

P4: I did skipping in listening but, if the text quite advances, I have nothing to do with that. I think skipping will not work. (4/ INT/4)

Skipping could help students in listening if they are quite familiar with the topic of the text because this strategy works altogether with the background knowledge of the students. If the students have nothing before, they will not be able to use this strategy maximally.

Also, the next listening strategy that the participants use is using imagery. By using this method, the students tried to imagine what they hear. They visualized the information to make the description clear. Through the result of think-aloud protocol, three participants applied this strategy.

P1: When there is an illustration or a diagram on my sheet that would help me to understand the text. I match what I heard with what I have seen. That eases me to understand the information and answer the questions. (1/INT/5) 
P2: I use not only picture but also back sound to make me understand the spoken text I usually apply that and that is useful. $(2 / I N T / 5)$

P3: I try my best to catch the information by relating what I have heard and make a clear picture of that inside my brain. (3/INT/5)

Those three participants use either picture on their answer sheet or back sound of the recording. Besides, they also imagined what they listen into visual picture inside their brain and then made an interpretation or concluded the overall idea. Through the investigation, it was shown that high-level students mostly applied this strategy. Hence, the use of visual and audio illustration can be used as a helping media for the students to easily understand the idea of a spoken text. It would ease them to get important information. The use of illustration was highly recommended to be applied in teaching listening for EFL students. The lecturer should guide the students to be more usual to apply this method.

\subsection{Discussion}

\subsubsection{Listening difficulties encountered by EFL Students and Their Listening Strategies}

From the investigation, it is concluded that the EFL students had several difficulties in listening. The difficulties were related to inadequate practice outside the classroom, short-term memory, homophones and speech rate. However, to tackle those difficulties the students also applied strategies. Their strategies, based on the observation, were note-taking, skipping and using imagery.

It is reported that all participants maintain their concentration during listening. In addition, the participants who are catogorized as high level and medium level use more strategies than those of the low level learners' participants. The low level learners' participants tend to use skipping and note-taking.

Those most used strategies were cognitive strategies and metacognitive strategies. Socio-affective strategies have less contribution in giving any effect in the context of EFL students because the environment is still not compatible. The participants also stated that, after listening class they just ignore it. Most of the participants started to concern about listening only if they would have a test while the others they had no idea what they had to do. The lecturer only gives them work book without the recording so they could not review or practice at home.

The strategies that the students used involve their prior knowledge when listening. The students would set their attention when the session started. They tried to make a good start and hoped not to ruin everything. They tried to understand the sentences, selected the important keywords by paying attention to the topic of the text. It means that the more they became familiar with the topic, the easier they would catch the key points. Therefore, note-taking was mostly used when they were trying to concentrate since writing several keywords did not bother them much.

Since listening need more effort to keep our concentration, the students need to master listening strategies that involve both metacognitive and their cognitive system. The difficulties related to speech rate, homophones, and short term memory could be tackled by those strategies. When they are listening, they will put their attention. They will make their cognitive system ready. Then, they will follow the stream and listen to the sentence. In this stage, they still use their cognitive strategies when they find unfamiliar 
words. It implies that the students will use bottom-up strategies. They will analyze words per words or sentence per sentence. Next, if they find an unfamiliar word, they will do skipping. After that, when they consider they find important points, they will jot them down on their paper. That metacognitive strategy keeps the students' concentration. That strategy also avoids students with their problem related to short term memory. If they do not write the keywords, they will forget and miss the important information. As a consequence, they will fail to answer the question.

The other strategy applied by the students is using imagery. Using imagery in listening means that we translate or instantly alter the aural input into a visual image. This strategy uses our cognitive ability and cognitive system. Moreover, this strategy is strongly related with the students' prior knowledge. Their brain will be automatically triggered when they listen to something familiar. We call this process as recalling information which has been previously saved by our brain. Unfortunately, this strategy does not work well if the students do not have any background knowledge at all. They will find difficulty when they only have text without additional illustrations. It explained why low-level learners do not use this strategy. They do not store information related to the text so that they cannot recall the information. Another possibility is that they overwhelmed to divide their concentration between imagining and seeking key points. Listening or reading much information will be useful and give a good effect on them. In addition, using imagery will be easier if there are illustrations on the students' paper such as an image or diagram. The students especially those who do not have previous information will understand faster by connecting what they have seen and what they listen to. Thus, since the use of imagery involves our memory and our prior knowledge, it would be better if student books and test sheets are provided with illustrations.

Related to the problem of listening opportunity, the teachers or the lecturers should provide the students with a conducive environment which can support their listening process. A good learning environment could promote the teaching-learning process. The ideal environment to give students an opportunity in learning listening should consist learning media that can be used by the students such as videotape, speaker, headphone, good internet access, a good source like English film, English song, CDs, etc. The students will become familiar with English only when they have good exposure to it. The exposure will affect them at least for the topic familiarity. The teachers can also provide the students with a chance or a link to the native speaker. They can ask them to communicate frequently to enable the students to have a listening opportunity. In addition, according to Kuraedah et al. (2018), a good learning environment is an environment that can inspire students and educators to reach the best version of them. A good learning environment should cover structures, tools, and communication. We should create such an environment to support the process of students' learning development. By creating a good learning environment, the teachers can make the students become better learners who are capable of manoeuvring themselves with learning strategies. Thus, a good learning environment is a must in the teaching-learning process.

\section{Conclusion}

Based on the data analysis, it can be concluded that EFL students find difficulties in listening. There are several difficulties encountered by Indonesian EFL learners. They are lack of opportunity, short-term memory, homophone and speech rate. The position of English as a foreign language does affect their listening comprehension. In Indonesia, English is positioned as a foreign language meaning that the 
students or the societies do not use it as a second means of communication. Indonesian people, especially the students prefer to use their first language.

From the think-aloud protocol procedure administered, the students at least proposed several strategies to tackle the problems. Those strategies are note-taking, skipping and using imagery. They did not use the other strategies because they were not familiar with them. The students used note-taking when they looked for the main idea. They only listened the important part of the text and wrote down the keywords on their paper. In listening, they skip the difficult words to maintain their concentration. Skipping also simplified their listening process. By skipping the difficult and unfamiliar word they would make the process of notetaking run well. Moreover, they also applied imagery as a strategy. However, this strategy of translating audio input into visual image inside our brain only applied by high-level students and medium level students. The application of imagery in our brain can be helpful since it will retain our memory longer and ease us to understand the information.

It can be inferred that the use of listening strategies is important since English is not frequently used as a means of communication by EFL learners in Indonesia. They exactly are going to find difficulties in either comprehending or in acquiring the language. The teachers should guide the students by giving them knowledge and guidance about the use of listening strategies so that they can make their learning goals and become successful learners. Moreover, this research hopefully enables the students to be more aware with their learning goals and also enable them to keep their motivation in learning. Next for the institutions, they can develop and provide the best learning facilities to support teaching and learning process.

\section{References}

Allan, D. (2004). Oxford Placement Test. Oxford: Oxford University Press.

Brindley, G., \& Slatyer, H. (2002). Exploring task difficulty in ESL listening assessment. Language Testing. (19), 369-394. doi:10.1191/02655322021t236oa

Brown, H. D. (2004). Language Assessment: Principles and Classroom Practices. White Plains, New York: Pearson Education.

Brown, H. D. (2007). Teaching by Principles. New York: Pearson Longman.

Buck, G. (2001). Assessing Listening. Cambridge, England: Cambridge University Press. doi:10.1017/CBO9780511732959.

Field, J. (2008) Listening in the Language Classroom. Cambridge, UK: Cambridge Univer.sity Press.

Chang, A. C.S., Wu, B.W. P., \& Pang, J. C. L. (2013). Second language listening difficulties perceived by low-level learners. Perceptual \& Motor Skills: Learning \& Memory, 116 (2), 415-434

Chou, M. H. (2016). Strategy use for listening in English as a foreign language: A comparison of academic and vocational high school students. TESOL Journal. 7 (3), 513-519. doi:10.1002/tesj. 214

Downs, L. J. (2008). Listening skills training. Washington, D.C.: American society for training and development.

Fauziati, E. (2007). Introduction to Methods and Approaches in Second or Foreign Language Teaching. Surakarta: Era Pustaka Utama.

Gilakjani, A., P., \& Sabouri, N. B. (2016). Learners' listening comprehension difficulties in English language learning: A literature review. Journal of English Language Teaching, 9(6), 123-133. doi:10.5539/elt.v9n6p123

Golchi, M. M. (2012). Listening anxiety and its relationship with listening strategy and listening comprehension among Iranian IELTS learners. International Journal of English Linguistics, 2. doi:10.5539/ijel.v2n4p115 
Goss, B. (1982). Listening as Information Processing. Communication Quarterly, 30, 304-307. doi:10.1080/014633782093669465.

Graham, S. (2006). Listening comprehension: The learners' perspective'. System, (34), 165-82.

Kuraedah, S., Gunawan, f., Wekke, I. S., \& Hammudin, B. (2018). Learning environment construction in islamic higher education: Connecting the puzzles of ideas. 175 (2018)012107. doi: 10.1088/1755-1315/175/1/012107. IOP Conference Series: Earth and Environmental Science.

Macaro, E., Graham, S., \& Vanderplank, R. (2007). A review of listening strategies: Focus on sources of knowledge and on success. Oxford: Oxford University Press.

O’Malley, M.J., \& A.U. Chamot. (1990). Learning strategies in second language acquisition. Cambridge: Cambridge University Press.

Oxford, R. L. (1990). Language learning strategies: What every teacher should know. New York: Newbury House.

Richards, J. C. (2005). Interchange Intro. 3rd ed. Cambridge: Cambridge University Press.

Rost, M. (2001). Teaching and Researching Listening. New York: Longman.

Rubin, J. (1995). An overview to a guide for the teaching of second language listening. In D. J.

Mendelsohn and J. Rubin (Eds.), A guide for the teaching of second language listening. (pp. 711). San Diego, California: Dominie Press, Inc.

Rost, M. (2001). Teaching and researching listening. New York: Longman.

Rost, M. (2009). Teacher development interactive: Listening. White Plains New York: Pearson Longman.

Samuels, S. J. (1984). Factors influencing listening: Inside and outside the head. Theory into Practice, 23, 183-189.

Serri, F., Boroujeni, A. J., \& Hesabi, A. (2012). Cognitive, metacognitive, and social/affective strategies in listening comprehension and their relationships with individual differences. Theory and Practice in Language Studies, 2. 10.4304/tpls.2.4.843-849

Sebina, B., \& Arua, A. E. (2014). From perception to knowledge to classroom practice: Teaching listening comprehension to Setswana speakers of English in junior schools in Botswana. International Journal of Listening. http://dx.doi.org/10.1080/10904018.2014.928212

Ulum, O, G. (2015). Listening: The ignored skill in EFL context. International Journal of Humanities Social Science and Education, 2(5), 72-80.

Ur, P. (1984). Teaching listening comprehension. Cambridge, England: Cambridge University Press.

Vandergrift, L. (2007). Recent developments in second and foreign language listening comprehension research.. Language Teaching. 40(3), 191-210. doi: $10.1017 / \mathrm{S} 0261444807004338$

Vandergrift, L., \& Goh, C. (2012). Teaching and learning second language listening: Metacognition in Action. New York: Routledge.

Wilson, J.J. (2009). How to teach listening. New York: Pearson Longman. 